\title{
Pengaruh Panjang Tabung dan Radius Fillet Terhadap Faktor Keamanan Tabung Motor Roket Dextrose Menggunakan Ansys Workbench
}

\author{
Lasinta Ari Nendra Wibawa ${ }^{*}$, Unggul Satrio Yudhotomo ${ }^{2}$, Yudi Haryanto ${ }^{3}$, Rahadyan Lingga Laksita ${ }^{4}$ \\ $1,2,3,4$ Lembaga Penerbangan dan Antariksa Nasional (LAPAN) \\ 1,2,3,4 Jln. Cilauteureun, Cikelet, Garut, 44175, Indonesia \\ E-mail: lasinta.ari@lapan.go.id ${ }^{1}$, unggul.satrio@lapan.go.id ${ }^{2}$, yudi.haryanto@lapan.go.id ${ }^{3}$, \\ rahadyan.lingga@lapan.go.id ${ }^{4}$
}

Info Naskah:

Naskah masuk: 15 April 2021

Direvisi: 17 Agustus 2021

Diterima: 19 Agustus 2021

\begin{abstract}
Abstrak
Tabung motor roket merupakan komponen utama pada roket Dextrose. Makalah ini bertujuan untuk menyelidiki pengaruh panjang tabung dan radius fillet terhadap faktor keamanan tabung motor roket dextrose menggunakan Ansys Workbench. Tabung roket Dextrose menggunakan material $\mathrm{Al}$ 6063-T5 dengan diameter luar $32 \mathrm{~mm}$, ketebalan dinding $3 \mathrm{~mm}$, dan tekanan internal 5 MPa. Panjang tabung roket divariasikan 200, 250, 300, dan $350 \mathrm{~mm}$. Radius fillet menggunakan variasi 3 , 4, dan $5 \mathrm{~mm}$. Analisis dilakukan menggunakan metode elemen hingga dengan bantuan Ansys Workbench. Hasil simulasi menunjukkan bahwa faktor keamanan tidak berpengaruh signifikan terhadap perubahan panjang tabung roket. Faktor keamanan meningkat seiring peningkatan radius fillet.
\end{abstract}

\section{Keywords:}

ansys workbench; rocket tube length; fillet radius; dextrose rocket; rocket motor tube.

\section{Abstract}

The rocket motor tube is the main component of the Dextrose rocket. This paper aims to investigate the effect of tube length and fillet radius on the safety factor of a dextrose rocket motor tube using Ansys Workbench. The Dextrose rocket tube uses Al 6063-T5 material with an outer diameter of $32 \mathrm{~mm}$, a wall thickness of $3 \mathrm{~mm}$, and internal pressure of $5 \mathrm{MPa}$. The rocket motor tube length is varied by 200, 250, 300, and $350 \mathrm{~mm}$. The fillet radius uses variations of 3,4 , and $5 \mathrm{~mm}$. The analysis was carried out using the finite element method with the help of Ansys Workbench. The simulation results show that the safety factor does not have a significant effect on changes in the length of the rocket tube. The safety factor increases as the fillet radius increases. 


\section{Pendahuluan}

Roket Dextrose adalah roket amatir yang menggunakan bahan bakar utama Kalium Nitrat $\left(\mathrm{KNO}_{3}\right)$ /Dextrose untuk menghasilkan gaya dorong. Kalium Nitrat yang merupakan bahan dasar pupuk dan dapat larut dalam air tersebut berfungsi sebagai oksidator. Dextrose yang merupakan gabungan antara gula sederhana dan air digunakan sebagai binder bahan bakar (fuel binder). Pada umumnya, rasio perbandingan antara Kalium Nitrat dan Dextrose adalah 65 persen banding 35 persen (13:7). Bahan bakar roket dari Kalium Nitrat/Dextrose (KNDX) ini banyak digunakan untuk penelitian roket amatir mahasiswa di berbagai belahan dunia, selain Kalium Nitrat/Sucrose (KNSU) dan Kalium Nitrat/Sorbitol (KNSB) [1]-[6].

Roket Dextrose dapat menjadi media pembelajaran tentang teknologi peroketan yang relatif murah selain roket air (water rocket). Beberapa kelebihan roket Dextrose dibandingkan dengan roket air yaitu kemampuan terbang yang lebih stabil dan jarak jangkau yang lebih jauh. Bahan bakar Kalium Nitrat $\left(\mathrm{KNO}_{3}\right) /$ Dextrose juga memiliki tingkat risiko ledakan lebih rendah dibandingkan dengan menggunakan propelan dari bahan HTPB (Hydroxyl-terminated polybutadiene).

Tabung motor roket merupakan komponen utama pada roket Dextrose. Tabung motor roket berperan penting karena berisi bahan bakar Kalium Nitrat/Dextrose yang jika dinyalakan dapat menghasilkan gaya dorong (thrust). Dengan demikian, proses perancangan tabung roket harus mempertimbangkan parameter yang paling optimal agar rancangan tabung roket dapat menahan beban di lingkungan kerjanya.

Panjang tabung roket dan radius fillet merupakan faktor yang berpengaruh terhadap tegangan von Mises maksimum pada silinder yang menggunakan prinsip bejana tekan [7], [8]. Panjang tabung roket juga sangat menentukan berapa banyak bahan bakar yang dibawa oleh roket Dextrose. Selain panjang tabung roket dan radius fillet, faktor lain seperti ketebalan cap, ketebalan dinding, dan tekanan internal roket juga mempengaruhi nilai tegangan von Mises maksimumnya [9]-[11]. Pada penelitian ini, ketebalan dinding, ketebalan cap, dan tekanan internal roket Dextrose konstan.

Tabung roket Dextrose dirancang menggunakan silinder berdinding tebal (thick-walled cylinder) dengan diameter luar $32 \mathrm{~mm}$ dan ketebalan dinding $3 \mathrm{~mm}$ seperti pada penelitian sebelumnya [12]. Radius fillet menggunakan variasi 3, 4, dan 5 $\mathrm{mm}$. Variasi panjang tabung yang digunakan yaitu 200, 250, 300, dan $350 \mathrm{~mm}$. Tekanan internal konstan, yaitu $5 \mathrm{MPa}$. Aluminium 6063-T5 yang memiliki massa jenis ringan $\left(2,85 \mathrm{~g} / \mathrm{cm}^{3}\right)$, harga relatif murah, kekuatan medium (yield strength $145 \mathrm{MPa}$ dan tensile strength $186 \mathrm{MPa}$ ), young modulus $68,9 \mathrm{MPa}$, dan mudah ditemukan di pasaran digunakan sebagai material tabung roket [12].

Simulasi tabung roket Dextrose dilakukan dengan Ansys Workbench menggunakan metode elemen hingga. Ansys Workbench adalah salah satu perangkat lunak yang cukup banyak digunakan untuk simulasi tabung motor roket dan pesawat terbang [7]-[13]. Keunggulan Ansys antara lain mudah saat diintegrasikan dengan hampir semua software perancangan 3 (tiga) Dimensi seperti SolidWorks, Catia, Autodesk Inventor, dan Creo.

\section{Metode}

Bejana tekan dibagi menjadi 2 (dua) berdasarkan dimensinya, yaitu berdinding tipis (thin-walled pressure vessel) dan berdinding tebal (thick-walled pressure vessel). Bejana tekan dengan ketebalan dinding lebih kecil dari 1/20 diameter dalamnya dikategorikan sebagai berdinding tipis, sedangkan bejana tekan dengan ketebalan dinding lebih besar dari 1/20 diameter dalamnya dikategorikan sebagai berdinding tebal.

Pada penelitian ini, tabung roket memiliki ketebalan dinding $3 \mathrm{~mm}$ sehingga dapat dikategorikan sebagai bejana tekan berdinding tebal karena ketebalan dinding lebih tinggi dari 1/20 diameter dalamnya, tepatnya $1 / 20 \times 26 \mathrm{~mm}=1,3 \mathrm{~mm}$. Pada kasus silinder berdinding tebal, tekanan yang terjadi pada dinding silinder tidak terdistribusi merata karena tegangan hoop dan tegangan radial nilainya sangat bergantung pada jari-jarinya [14].

Teori Elastisitas merupakan salah satu teori pokok yang digunakan untuk menyelesaikan persoalan silinder berdinding tebal (thick-walled cylinder) yang menghasilkan kondisi tegangan sebagai fungsi kontinyu dari jari-jari di atas dinding bejana tekan [15]. Rasio antara jari-jari dalam dan jari-jari luar $\left(\mathrm{r}_{\mathrm{o}} / \mathrm{r}_{\mathrm{i}}\right)$ berpengaruh terhadap tegangan dalam bejana tekan.

Tegangan yang terjadi pada silinder berdinding tebal terjadi pada 3 arah, yaitu hoop stress, longitudinal stress, dan radial stress.

$$
\begin{aligned}
& \left(\sigma_{h}\right)_{\max }=p_{i}\left(\frac{r_{i}^{2}+r_{i}^{2}}{r_{0}^{2}-r_{i}^{2}}\right) \\
& \left(\sigma_{i}\right)_{\max }=p_{i}\left(\frac{r_{i}^{2}}{r_{0}^{2}-r_{i}^{2}}\right) \\
& \left(\sigma_{y}\right)_{\max }=-p_{i}
\end{aligned}
$$

Di mana $r_{i}=$ jari-jari dalam silinder $(\mathrm{mm}), \mathrm{r}_{\mathrm{o}}=$ jari-jari luar silinder $(\mathrm{mm})$, dan $\mathrm{p}_{\mathrm{i}}=$ tekanan internal $(\mathrm{MPa})$,

Gambar 1 menunjukkan desain silinder tabung roket Dextrose. Tabung roket yang memiliki bentuk silinder dapat dimodelkan dengan setengah bagian atasnya [16]. Simulasi pada penelitian ini cukup menggunakan bagian seperdelapan silinder padat. Hal ini dapat dilakukan karena tekanan yang diberikan pada fluida dalam silinder tertutup maka tekanan tersebut akan diteruskan merata ke semua arah dan sama besar [17]. Pemodelan menggunakan seperdelapan silinder juga dapat menghemat waktu komputasi karena proses meshing dapat dilakukan lebih cepat dan akurat.

Gambar 2 menjelaskan kondisi batas untuk analisis tabung motor roket Dextrose menggunakan perangkat lunak Ansys Workbench. Tabel 1 menunjukkan parameter simulasi menggunakan Ansys Workbench. Ukuran elemen yang digunakan dalam simulasi pada penelitian ini diatur seragam, yaitu $1,5 \mathrm{~mm}$. Hal ini mengakibatkan jumlah node dan elemen untuk masing-masing variabel panjang tabung dan radius fillet ada perbedaan yang ditunjukkan pada Tabel 2 . 


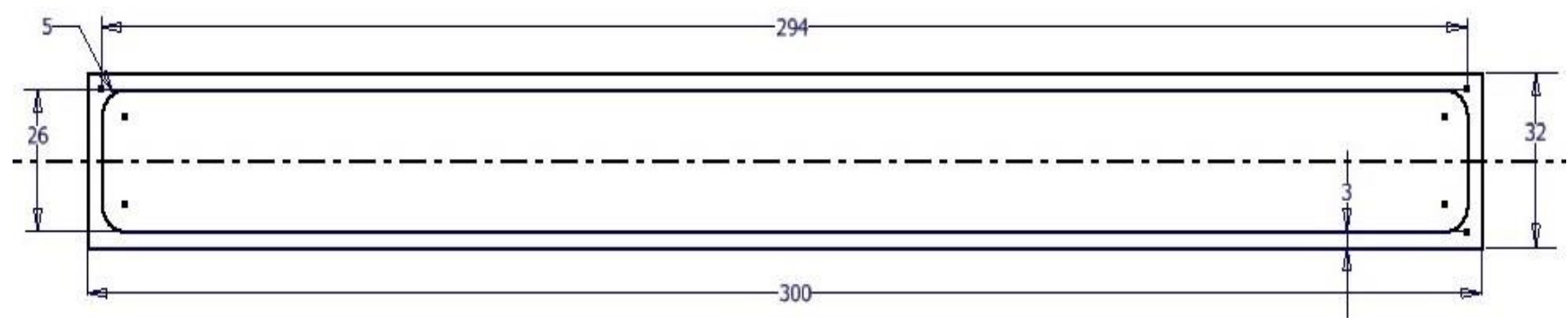

Gambar 1. Desain tabung roket Dextrose dengan diameter luar $32 \mathrm{~mm}$, radius fillet $5 \mathrm{~mm}$, ketebalan dinding $3 \mathrm{~mm}$, dan panjang $300 \mathrm{~mm}$.

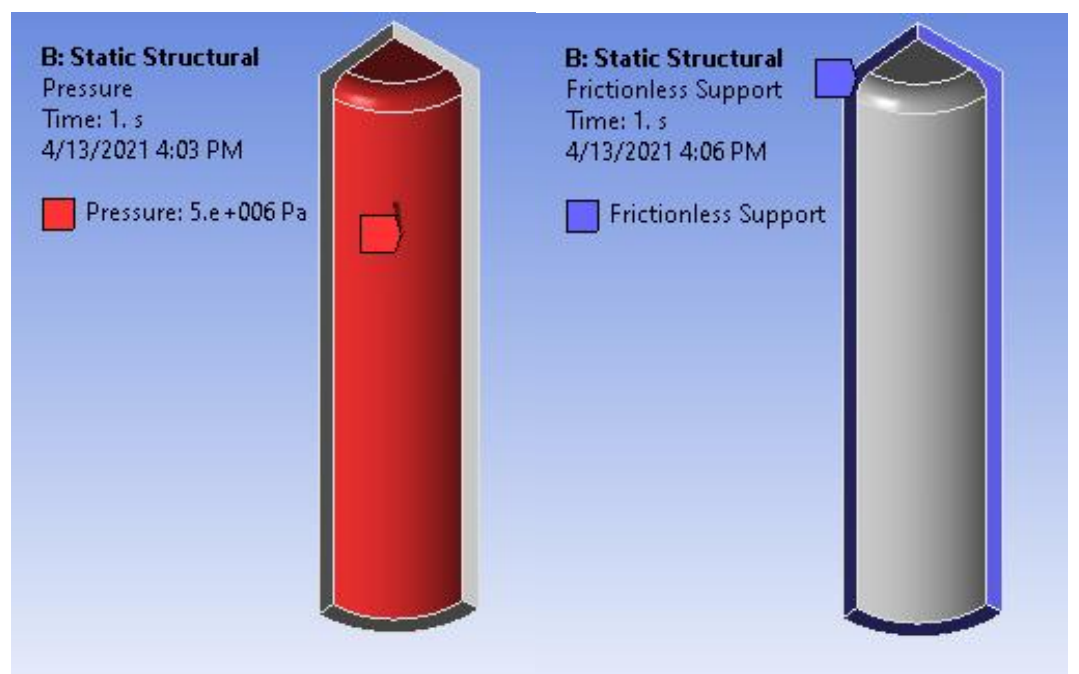

Gambar 2. Kondisi batas: kondisi pembebanan (kiri) dan jenis constraint (kanan).

Tabel 1. Parameter simulasi menggunakan Ansys Workbench.

\begin{tabular}{lc}
\hline \multicolumn{1}{c}{ Parameter } & Keterangan \\
\hline Diameter luar & $32 \mathrm{~mm}$ \\
Panjang tabung & $200,250,300$, dan $350 \mathrm{~mm}$ \\
Radius fillet & 3,4, dan $5 \mathrm{~mm}$ \\
Ketebalan dinding & $3 \mathrm{~mm}$ \\
Tekanan internal & $5 \mathrm{MPa}$ \\
Ukuran elemen & $1,5 \mathrm{~mm}$ \\
\hline
\end{tabular}

Tabel 2. Jumlah node dan elemen untuk variasi radius fillet dan panjang tabung roket Dextrose.

\begin{tabular}{cccc}
\hline Radius fillet $(\mathbf{m m})$ & Panjang tabung $(\mathbf{m m})$ & Jumlah node & Jumlah elemen \\
\hline 3 & 200 & 15447 & 8359 \\
3 & 250 & 18257 & 9856 \\
3 & 300 & 23279 & 12616 \\
3 & 350 & 25728 & 13989 \\
4 & 200 & 14832 & 8018 \\
4 & 250 & 17821 & 9682 \\
4 & 300 & 23046 & 12511 \\
4 & 350 & 25278 & 13727 \\
5 & 200 & 14963 & 8113 \\
5 & 250 & 17881 & 9697 \\
5 & 300 & 23348 & 12651 \\
5 & 350 & 25176 & 13647 \\
\hline
\end{tabular}




\section{Hasil dan Pembahasan}

Gambar 3 menggambarkan pengaruh panjang tabung 300 $\mathrm{mm}$ (atas) dan $350 \mathrm{~mm}$ (bawah) dengan radius fillet $5 \mathrm{~mm}$ terhadap tegangan von Mises tabung roket Dextrose yang hasilnya berturut-turut 47,50 $\mathrm{MPa}$ dan 47,57 $\mathrm{MPa}$. Hal ini membuktikan bahwa tegangan von Mises maksimum tidak mengalami kenaikan signifikan seiring peningkatan panjang tabung roket yang ditunjukkan pada Gambar 5 .

Gambar 4 menggambarkan tegangan von Mises untuk panjang tabung roket $200 \mathrm{~mm}$ dengan radius fillet $3 \mathrm{~mm}$ (atas) dan $4 \mathrm{~mm}$ (bawah) berturut-turut 57,89 $\mathrm{MPa}$ dan 52,60 MPa. Gambar tersebut membuktikan semakin tinggi radius fillet, semakin rendah tegangan von Mises maksimumnya. Hal ini berarti tegangan von Mises maksimum dapat diminimalkan dengan menaikkan nilai radius fillet, tanpa menaikkan ketebalan dinding tabung roket [7], [8]. Dengan demikian, menaikkan radius fillet dapat mengurangi berat tabung roket dibanding meningkatkan ketebalan tabung roket secara keseluruhan.

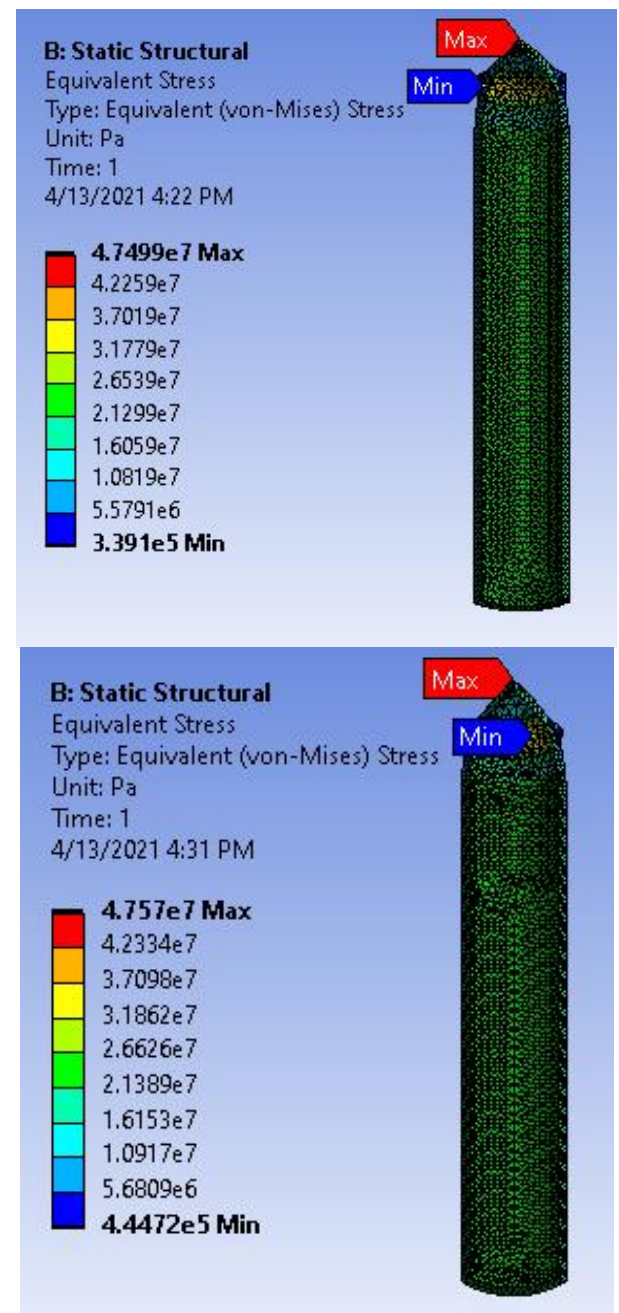

Gambar 3. Tegangan von Mises untuk radius fillet $5 \mathrm{~mm}$ dengan panjang tabung $300 \mathrm{~mm}$ (atas) dan $350 \mathrm{~mm}$ (bawah).
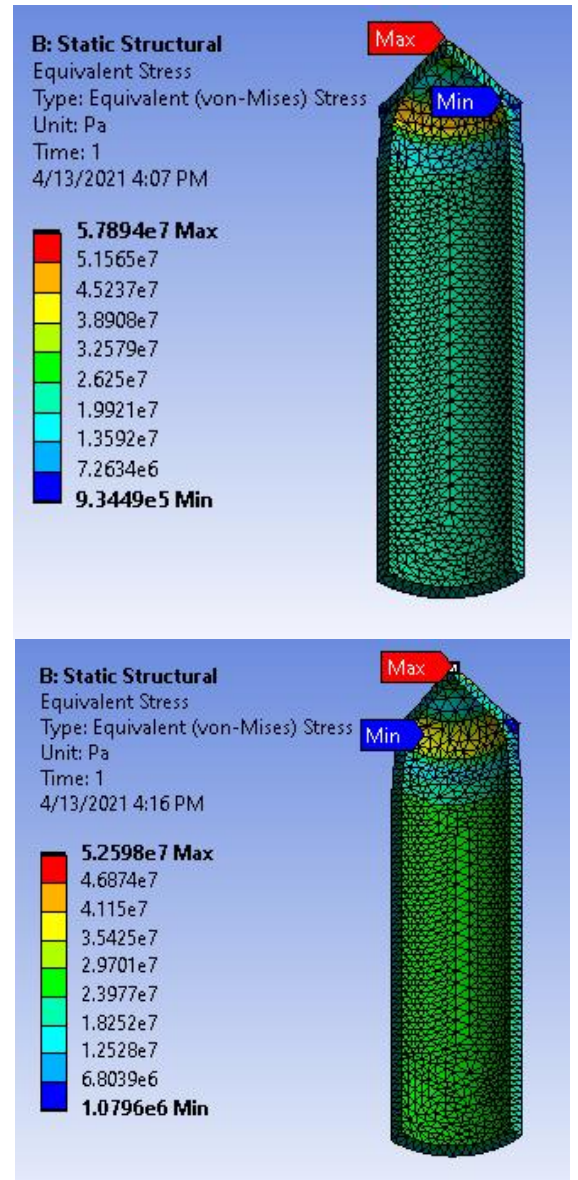

Gambar 4. Tegangan von Mises untuk panjang tabung roket 200 $\mathrm{mm}$ dengan radius fillet $3 \mathrm{~mm}$ (atas) dan $4 \mathrm{~mm}$ (bawah).

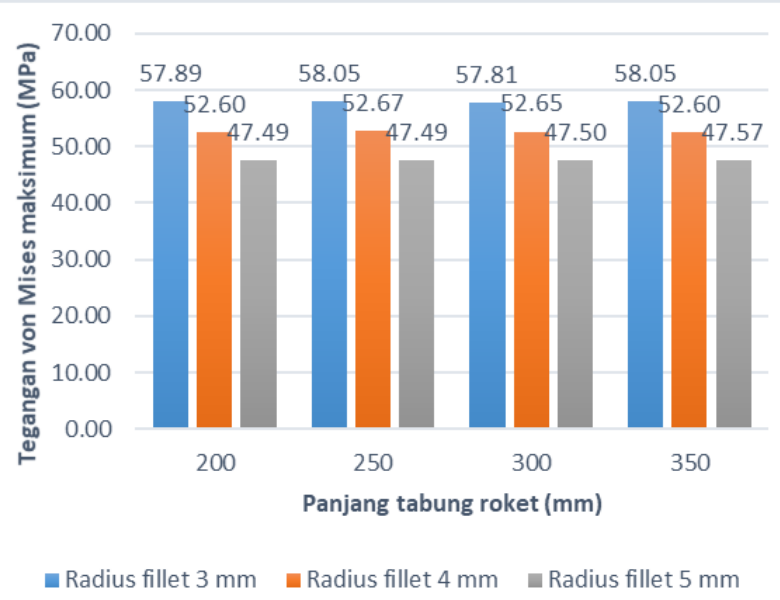

Gambar 5. Pengaruh panjang tabung dan radius fillet terhadap tegangan von Mises maksimum tabung roket Dextrose.

Faktor keamanan merupakan salah satu kriteria yang digunakan untuk memastikan apakah desain dari suatu komponen cukup aman saat diberikan beban sesuai kondisi kerjanya. Faktor keamanan dapat menggunakan salah satu dari batas kekuatan tarik maksimum (tensile strength) atau kekuatan luluh (yield strength) dari material tergantung sifat komponen. Komponen yang digunakan berulang-ulang menggunakan batas kekuatan luluh material, sedangkan 
komponen habis pakai dapat menggunakan kekuatan tarik maksimum. Faktor keamanan pada penelitian ini menggunakan kekuatan tarik maksimum karena tabung roket Dextrose merupakan komponen habis pakai [7].

Gambar 6 menunjukkan pengaruh panjang tabung roket dan radius fillet terhadap faktor keamanan minimum tabung roket Dextrose. Hasil simulasi menunjukkan faktor keamanan tidak berpengaruh signifikan terhadap perubahan panjang tabung roket [8]. Hal ini berbeda dengan perubahan radius fillet. Semakin tinggi radius fillet, maka semakin tinggi faktor keamanan.

Hasil simulasi elemen hingga menunjukkan untuk semua variasi panjang tabung dan radius fillet memiliki faktor keamanan lebih dari 3,00. Kondisi ini berarti tabung roket dapat menahan beban kejut (impact load) karena nilai faktor keamanan untuk struktur mampu menahan beban kejut adalah 3,00-4,00 [18].

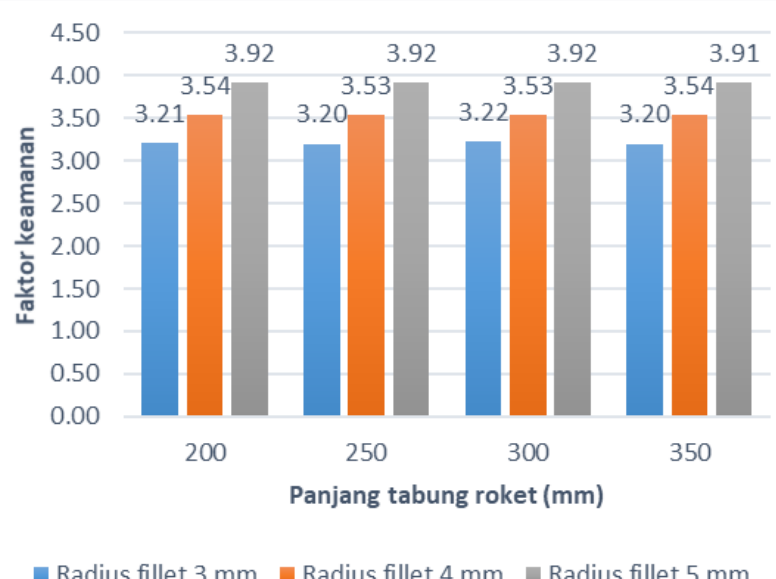

Gambar 6. Pengaruh panjang tabung dan radius fillet terhadap faktor keamanan minimum tabung roket Dextrose.

\section{Kesimpulan}

Hasil simulasi menggunakan Ansys Workbench menunjukkan bahwa faktor keamanan tidak berpengaruh signifikan terhadap perubahan panjang tabung roket. Hal ini berbeda dengan perubahan radius fillet. Faktor keamanan meningkat seiring peningkatan radius fillet.

\section{Daftar Pustaka}

[1] B. Huseyin, S. Çoban, and A. Yapıc1, "Designing, Modeling and Simulation of Solid Fuel Rocket ALP-01," Eur. J. Sci. Technol., no. 15, pp. 511-518, 2019.

[2] D. A. Singh, "Sugar Based Rocket Propulsion SystemMaking, Analysis \& Limitations," Int. J. Eng. Trends Appl., vol. 2 , no. 5, pp. 30-37, 2013.

[3] B. Aliyu, C. Osheku, E. Oyedeji, M. Adetoro, A. Okon, and C. Idoko, "Validating a Novel Theoretical Expression for Burn time and Average Thrust in Solid Rocket Motor Design," Adv. Res., vol. 5, no. 4, pp. 1-11, 2015.
[4] G. O. Adeniyi, I. Nkere, L. M. Adetoro, and O. S. Sholiyi, "Performance Analysis of a Dual-Fuel Sugar Based Solid Rocket Propellant," Eur. J. Eng. Technol. Res., vol. 6, no. 2, pp. 34-41, 2021.

[5] C. Américo, D. F. Moro, C. H. Marchi, and F. Aguiar, "Development of a Ballistic Evaluation Motor for Knsu Burn Rate Measurements," in 18th Brazilian Congress of Thermal Sciences and Engineering, 2020, vol. 2020.

[6] R. R. Salazar et al., "Design, construction and experimental static testing of a solid rocket motor," Rev. UIS Ing., vol. 20, no. 2, pp. 97-108, 2021.

[7] L. A. N. Wibawa, "Studi Numerik Pengaruh Radius Fillet dan Ketebalan Cap terhadap Tegangan Von Mises dan Faktor Keamanan Silinder Berdinding Tipis untuk Tabung Motor Roket," J. Rekayasa Mesin, vol. 15, no. 1, pp. 1-9, 2020.

[8] L. A. N. Wibawa, K. Diharjo, W. Raharjo, and B. H. Jihad, "The Effect of Fillet Radius and Length of The ThickWalled Cylinder on Von Mises Stress and Safety Factor for Rocket Motor Case," AIP Conf. Proc., vol. 2296, no. 1, 2020.

[9] L. A. N. Wibawa, K. Diharjo, W. W. Raharjo, and B. H. Jihad, "Stress Analysis of Thick-Walled Cylinder for Rocket Motor Case under Internal Pressure," J. Adv. Res. Fluid Mech. Therm. Sci., vol. 70, no. 2, pp. 106-115, 2020.

[10] L. A. N. Wibawa, K. Diharjo, W. W. Raharjo, and B. H. Jihad, "Pengaruh Ketebalan Cap dan Tekanan Internal terhadap Tegangan Von Mises Silinder Berdinding Tebal untuk Tabung Motor Roket," Teknik, vol. 41, no. 2, pp. 111$118,2020$.

[11] L. A. N. Wibawa, "Numerical Study of The Effect of Wall Thickness and Internal Pressure on Von Mises Stress and Safety Factor of Thin-Walled Cylinder for Rocket Motor Case," JST (Jurnal Sains dan Teknol., vol. 9, no. 1, pp. 30 $38,2020$.

[12] L. A. N. Wibawa, U. S. Yudhotomo, Y. Haryanto, and A. Kurniawan, "Pengaruh Ketebalan Dinding dan Tekanan Internal terhadap Faktor Keamanan Tabung Motor Roket Dextrose Menggunakan Ansys Workbench," Media Mesin Maj. Tek. Mesin, vol. 22, no. 2, pp. 76-84, 2021.

[13] L. A. N. Wibawa, K. Diharjo, W. W. Raharjo, Z. Arifin, D. Ariawan, and B. H. Jihad, "Effect of Overlap Length and Surface Roughness on Adhesive Joint Strength of Composite Rocket Motor Case (GFRP) and Cap (Al 6061)," J. Phys. Conf. Ser., 2021.

[14] R. S. Khurmi and J. K. Gupta, A textbook of machine design, 14th ed., no. I. New Delhi: Eurasia Publishing House, 2005.

[15] Q. S. Masikh, M. Tariq, and P. K. Sinha, "Analysis of A Thin and Thick Walled Pressure Vessel for Different Materials," Int. J. Mech. Eng. Technol., vol. 5, no. 10, pp. 919, 2014.

[16] F. Dadkhah and J. Zecher, ANSYS Workbench Software Tutorial with Multimedia $C D$ Release 11. Schroff Development Corporation, 2008.

[17] K. L. Lawrence, Ansys Workbench Tutorial Release 14. Schroff Development Corporation, 2012.

[18] V. Dobrovolsky and K. Zablonsky, Machine elements : a textbook. Moscow: Peace Publisher, 1978. 